\title{
Projected changes in extreme precipitation over Scotland and Northern England using a high-resolution regional climate model
}

\author{
Steven C. Chan ${ }^{1} \cdot$ Ron Kahana ${ }^{2}$ - Elizabeth J. Kendon ${ }^{2} \cdot$ Hayley J. Fowler $^{1}$
}

Received: 24 July 2017 / Accepted: 2 January 2018 / Published online: 14 March 2018

(c) Crown 2018

\begin{abstract}
The UK Met Office has previously conducted convection-permitting climate simulations over the southern UK (Kendon et al. in Nat Clim Change 4:570-576, 2014). The southern UK simulations have been followed up by a new set of northern UK simulations using the same model configuration. Here we present the mean and extreme precipitation projections from these new simulations. Relative to the southern UK, the northern UK projections show a greater summertime increase of return levels and extreme precipitation intensity in both $1.5 \mathrm{~km}$ convection-permitting and $12 \mathrm{~km}$ convection-parameterised simulations, but this increase is against a backdrop of large decreases in summertime mean precipitation and precipitation frequency. Similar to the southern UK, projected change is model resolution dependent and the convection-permitting simulation projects a larger intensification. For winter, return level increases are somewhat lower than for the southern UK. Analysis of model biases highlight challenges in simulating the diurnal cycle over high terrain, sensitivity to domain size and driving-GCM biases, and quality issues of radar precipitation observations, which are relevant to the wider regional climate modelling community.
\end{abstract}

\section{Introduction}

In two previous papers (Chan et al. 2014a; Kendon et al. 2014), we have diagnosed extreme precipitation projections for the southern UK (SUK) from a set of 12 and $1.5 \mathrm{~km}$ regional climate model (RCM) simulations conducted with the UK Met Office (UKMO) Unified Model (UM). A new set of $1.5 \mathrm{~km}$ convection-permitting model (CPM) and $12 \mathrm{~km}$ parameterised-convection model (PCM) simulations that focus on northern England and Scotland (northern UK; NUK) were completed in 2016 for a study predicting future changes in nutrient transfer in small river catchments (project NUTCAT2050; Ockenden et al. 2016). These new

The author Steven C. Chan is a visiting scientist at the Met Office Hadley Centre.

Electronic supplementary material The online version of this article (https://doi.org/10.1007/s00382-018-4096-4) contains supplementary material, which is available to authorized users.

Steven C. Chan

steven.chan@metoffice.gov.uk

1 School of Engineering, Newcastle University, Newcastle upon Tyne, UK

2 Met Office Hadley Centre, Exeter, UK simulations are driven by the same general circulation model (GCM) simulations (Mizielinski et al. 2014) used in the SUK study.

The main objective here is to summarise precipitation biases and projections for NUK, and compare them with previous SUK results. This provides full UK coverage for our projections from the same $12 \mathrm{~km} \mathrm{PCM}$ and $1.5 \mathrm{~km} \mathrm{CPM}$ one-way dynamic downscaling system. UKMO is currently conducting the next generation of CPM climate simulations for UK and Europe with updated UM physics for future UK climate projections (project UKCP18; UKCP 2017) and CORDEX flagship pilot studies (Giorgi et al. 2009). In the case of UKCP18, the first ensemble of CPM climate simulations will be carried out, UK wide, for delivery in 2018. Previous SUK and the new results presented here can be used to benchmark these newer simulations.

We begin with a brief description of our model simulations and observations (Sect. 2), followed by a summary of our methods (Sect. 3). The first two parts of our comparison section (Sect. 4.1-4.2) focus on the basic mean biases and projections for the NUK $1.5 \mathrm{~km}$ simulation. We then examine the frequencies and intensities of hourly precipitation (Sect. 4.3), diurnal cycles (Sect. 4.4), and lastly return levels of extremes (Sect. 4.5). 
Fig. 1 The $1.5 \mathrm{~km}$ simulation domain for NUK with surface height ( $\mathrm{m}$, above sea level) contoured. Scottish Highlands, Scottish Central Lowlands, and the Lake District are marked with $\mathrm{SH}, \mathrm{CL}$, and $\mathrm{LD}$, respectively. Currently operating (five sites) and former (only one site, south of Glasgow) precipitation radar sites within the simulation domain are marked with up and down triangles, respectively. Major cities and points of interest (POI) are marked as well
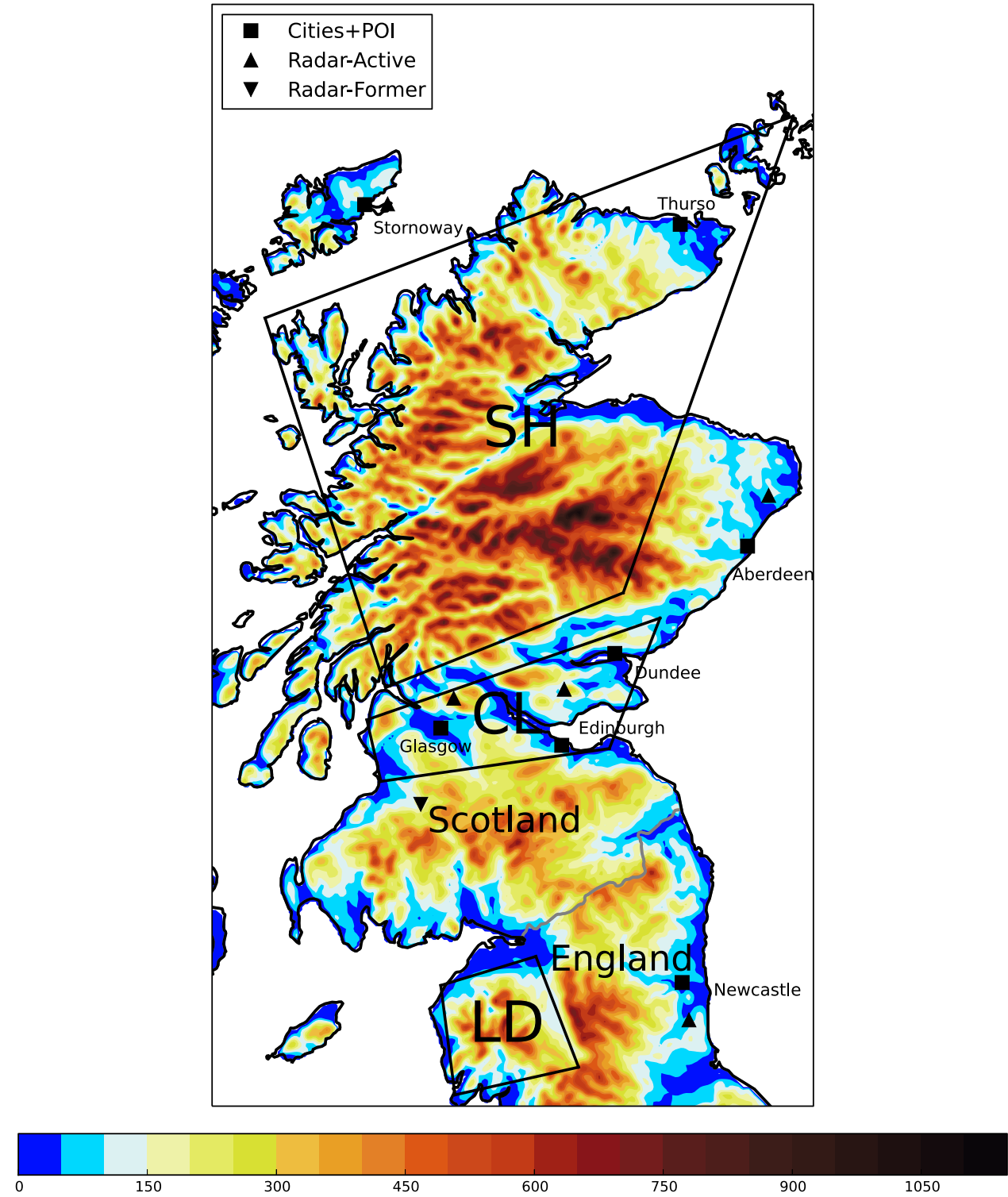

\section{Model and observations}

The new NUK 13-year CPM simulation domain is centred over Scotland (Fig. 1). The new simulations have the same model physics as the previous SUK simulations (Kendon et al. 2012, 2014). The SUK and NUK simulations partially overlap over the northern half of England. This overlapping region is close to the boundary of both simulations, and is impacted by lateral boundary artefacts. Hence, results from this region are not included in our analysis. Due to the proximity of Northern Ireland to the lateral boundary, Northern Ireland is also excluded from our analysis.

The SUK and the NUK are 13-years simulations and are one-way nested down from $12 \mathrm{~km}$ European RCM, driven by the present- and future-climate (end of twenty-first century for the RCP8.5 scenario) GCM simulations (Meinshausen et al. 2011; Mizielinski et al. 2014). ${ }^{1}$ The present-climate GCM simulations are driven by observed SST and sea ice between 1997 and 2009 (Donlon et al. 2012). Multi-year mean SST and sea ice projections, for each month, from an independent HadGEM2 coupled ocean-atmosphere GCM simulation are then superposed onto the observed daily SST and sea ice to give the lower boundary conditions for the future GCM simulation ${ }^{2}$ (Mizielinski et al. 2014). Both the 1.5 and $12 \mathrm{~km}$ simulations are analysed here. Unlike SUK simulations, we do not have a $1.5 \mathrm{~km}$ ERA-Interim-driven

\footnotetext{
1 An ERA-Interim (Dee et al. 2011) $12 \mathrm{~km}$ hindcast simulation is also available.

${ }^{2}$ Interpolated SSTs are used for sea ice free area.
} 
(Dee et al. 2011) hindcast simulation; hence, biases are diagnosed by comparing observations with the present-climate simulations. For the sake of comparison, observations and the $1.5 \mathrm{~km}$ CPM data are all regridded to the $12 \mathrm{~km}$ grid using area averaging.

Observations are used to examine the quality of the present-climate simulation. We use gridded hourly radar (RAD, 2003-2015; Harrison et al. 2000) and gridded daily gauge (UK5, 1962-2012; Perry et al. 2009) data. The two datasets have different $5 \mathrm{~km}$ grids, and both are regridded to a common $12 \mathrm{~km}$ grid for comparison. The UK5 northern UK gauge density is considerable lower than the $5 \mathrm{~km}$ "resolution" of the dataset (Perry et al. 2009), which further justifies the use of a lower resolution grid. As the simulations are not driven by reanalysis ("hindcast simulations"), the exact years for the observational data do not need to match. We would not expect correspondence between the models and observations on an event-by-event basis, but the climatology of hourly and daily precipitation accumulated over $10+$ years should be well captured.

Both in situ gauge and radar remote-sensing coverage ${ }^{3}$ over NUK are sparser than SUK, and complex terrain further complicates the problem. Radar data checks indicate about $15 \%$ of radar observations for the SUK domain are marked as missing, but this fraction increases to $25 \%$ for the NUK domain. There are no radar sites in the Scottish Highlands, and closest radar stations are near to Aberdeen and Stornoway (Harrison et al. 2000). For the UK5 observations, the current highest density of gauges is located along the Glasgow-Edinburgh corridor, and the density decreases north and southward toward the Highlands and rural English-Scottish border. Highland gauges tend to concentrate near coastal inlets ("firths"), settlements, and valleys. Gauge coverage is relatively poor in the early data period (1960s) with only about 20-some gauges north of Glasgow and Edinburgh (island gauges included).

\section{Methodologies and metrics}

Our primary focus here is on precipitation, and our results include many of the mean and extreme metrics that we have used to analyse the SUK simulations (Chan et al. 2013, 2014b). These include the summer (JJA) and winter (DJF) daily precipitation means ( $\mathrm{mm} /$ days), the number of "wet hours" (accumulated precipitation exceeds $0.1 \mathrm{~mm} / \mathrm{h}$ ) and a number of "wet hour" metrics: precipitation frequency, mean precipitation intensity, and precipitation intensity probability distribution. Total mean precipitation can be expressed as the sum of the mean intensity above the "wet" threshold

\footnotetext{
${ }^{3}$ Northern UK radar sites are marked in Fig. 1.
}

times the frequency of "wet hours", plus the remainder that is truncated below the threshold. Many observations have higher minimum thresholds than $0.1 \mathrm{~mm} / \mathrm{h}$; for instance, many UK tipping bucket gauges have $0.2 \mathrm{~mm}$ ticks (Blenkinsop et al. 2017).

Return levels and periods are standard metrics for extreme risk assessments, and are estimated using extreme value theory (Coles 2001). Return levels and periods are estimated using the peaks-over-threshold (POT; Chan et al. 2014a; Coles 2001; Martins and Stedinger 2001) method. The methodology is mostly unchanged from previous work (Chan et al. 2014a) except we increase the wet-hour extreme percentile threshold from 95.0 to 97.5 for $1 \mathrm{~h}$ precipitation extremes to account for the higher frequency of precipitation in NUK relative to SUK. The wet-day ${ }^{4}$ extreme percentile threshold (95.0) remains the same.

Previously published SUK projections focus mainly on extreme changes (Chan et al. 2014a; Kendon et al. 2014). We now also provide the mean changes for SUK in the Supplementary Material (Supplementary Figs. 1 and 2) to compare with the mean precipitation changes in NUK simulations.

\section{Results}

\subsection{Mean biases}

Figures 2 and 3 present the simulated summer and winter seasonal means of daily precipitation in the 1.5 and $12 \mathrm{~km}$ models, and compare them with a) the UK5 observations and b) future projections. Both models capture well the high values over the Scottish Highlands and the NW-SE precipitation gradient as shown by the observations.

When compared with observations, precipitation in the $1.5 \mathrm{~km}$ simulation is lower in the wettest regions along the west coast, and higher in the drier eastern regions. The dry bias in the west is more prominent in the winter months (Fig. 3c), while the wet bias in the east is more prominent in the summer months (Fig. 2c). In contrast, the $12 \mathrm{~km}$ simulation is slightly wetter than observations over most of the domain in summer, and is drier, mainly over central and eastern Scotland, in winter.

As the $1.5 \mathrm{~km}$ simulation dry biases appear over high terrain, we first hypothesised that the decreased precipitation rates are associated with orographic precipitation. However, a close inspection shows that the GCM-driven $1.5 \mathrm{~km}$ and $12 \mathrm{~km}$ southern UK simulations show a similar negative bias over the Welsh mountains and Cornwall, and positive biases in low lands to the east (Supplementary Figs. 1 and 2). It is possible then, that in both cases, the biases are inherited

\footnotetext{
${ }^{4}$ Days with precipitation exceeding $0.1 \mathrm{~mm} /$ days.
} 
Fig. 2 Summer mean daily precipitation from the $1.5 \mathrm{~km} \mathrm{CPM}$ for the present-day (a), future (d) and observed UK5 data (b). Same information for the $12 \mathrm{~km}$ $\mathrm{RCM}$ is presented in $(\mathbf{f}, \mathbf{g}, \mathbf{i})$. Ratios between the model and observations and between future and present day simulations are given as a ratio in (c) and (e) respectively for the $1.5 \mathrm{~km} \mathrm{CPM}$ and $(\mathbf{h}, \mathbf{j})$ for the $12 \mathrm{~km} \mathrm{RCM}$

\section{Summer daily mean precipitation $(\mathrm{mm} / \mathrm{d})$}

(a) RCM1.5_PRESENT: median $=\overline{3} .15 \mathrm{~mm}$

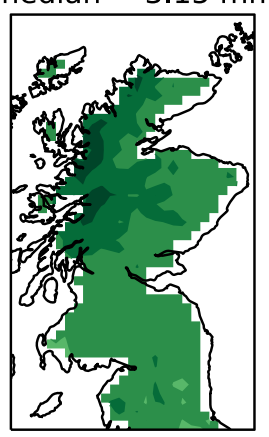

(d) RCM1.5_FUTURE_: median $=\overline{1} .92 \mathrm{~mm}^{-}$

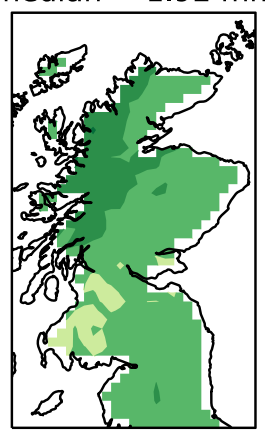

(f) RCM_PRESENT12: median $=3.16 \mathrm{~mm}$

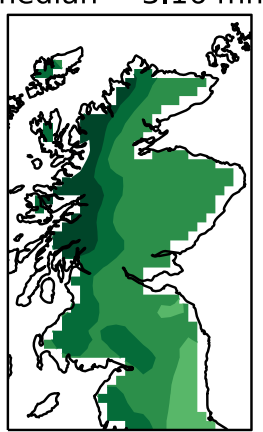

(i) RCM_FUTURE_12: median $=2.17 \overline{\mathrm{mm}}$
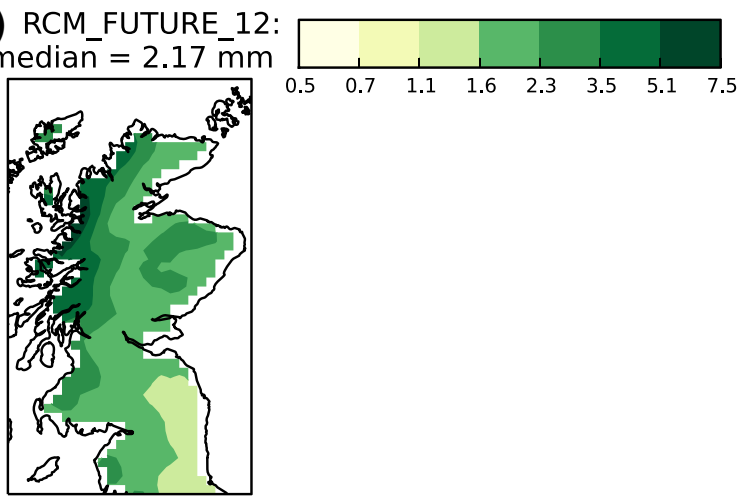

(b) OBS:

median $=2.94 \mathrm{~mm}$

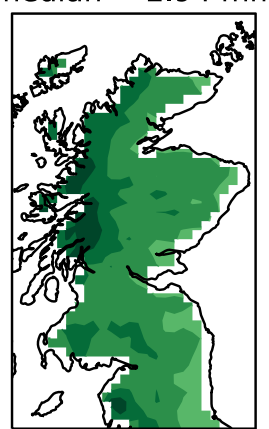

(g) OBS:

median $=2.94 \mathrm{~mm}$

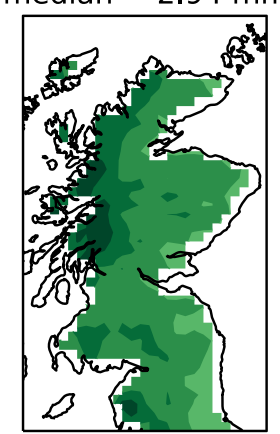

(c) PRESENT/OBS : median $=1.11$

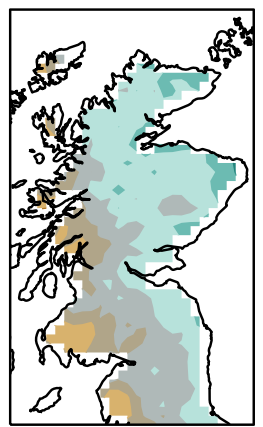

(e) FUT_1.5/PRES1.5 : median $=0.61$

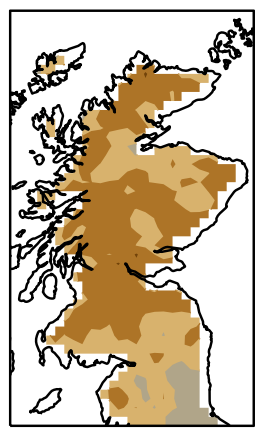

(h) PRESENT12/OBS : median $=1.1$

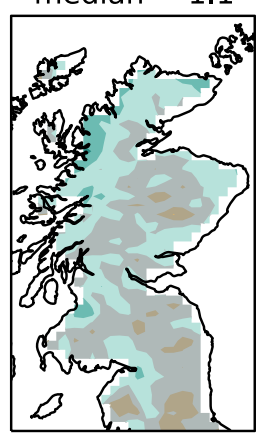

(j) FUT 12/PRES12 : median $=0.68$

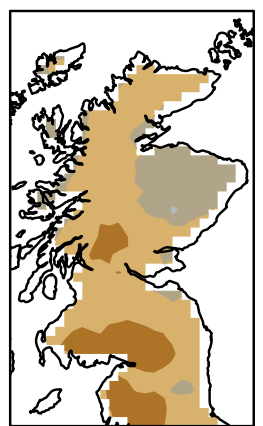

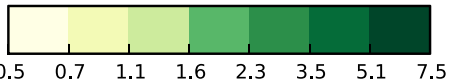


Fig. 3 Same as in Fig. 2, but for winter

\section{Winter daily mean precipitation $(\mathrm{mm} / \mathrm{d})$}

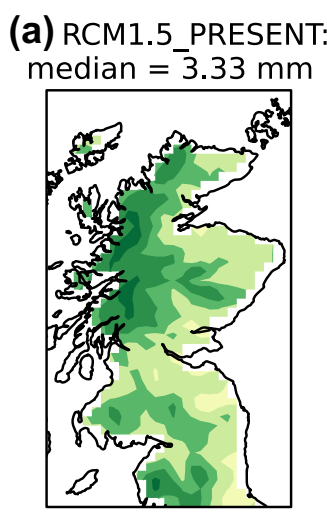

(d) RCM1.5_FUTURE_: median $=3.66 \mathrm{~mm}$

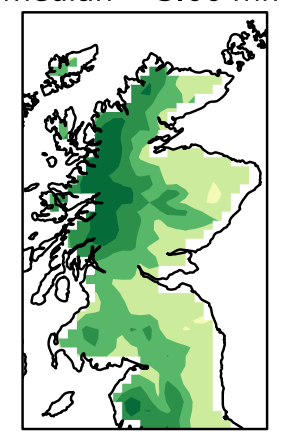

(f) RCM_PRESENT12: median $=3.7 \mathrm{~mm}$

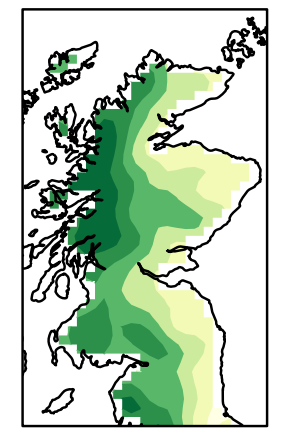

(i) RCM_FUTURE_12: median $=5.07 \mathrm{~mm}$

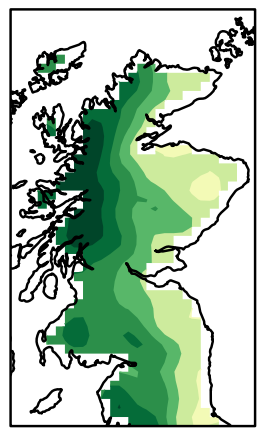

(g) OBS:

median $=4.16 \mathrm{~mm}$
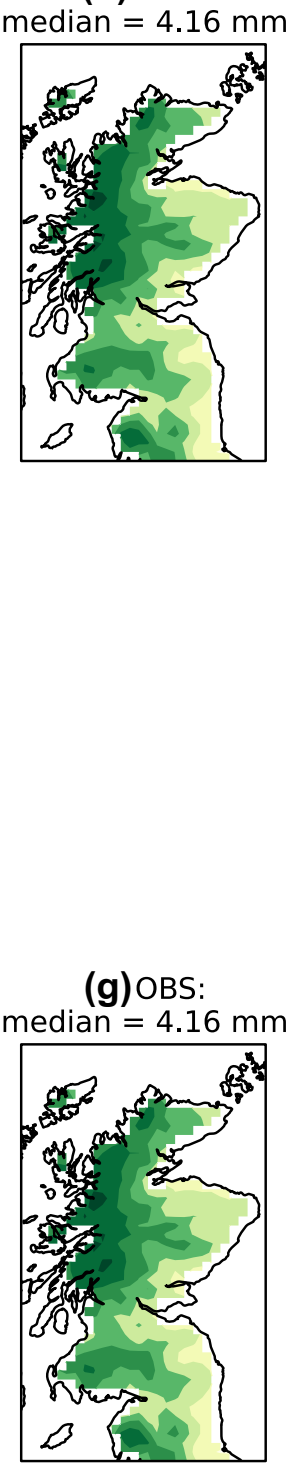

(c) PRESENT/OBS :

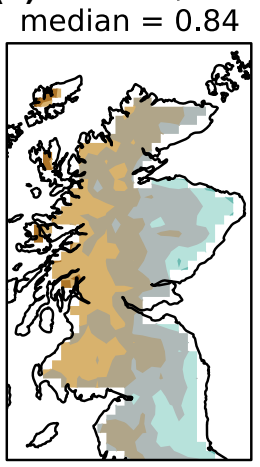

(e) FUT_1.5/PRES1.5 :

median $=1.13$

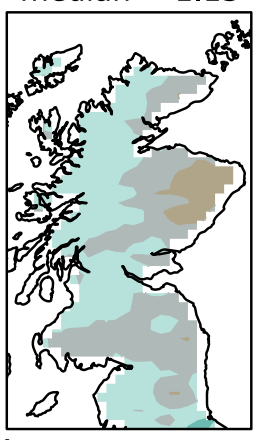

(h) PRESENT12/OBS : median $=0.87$

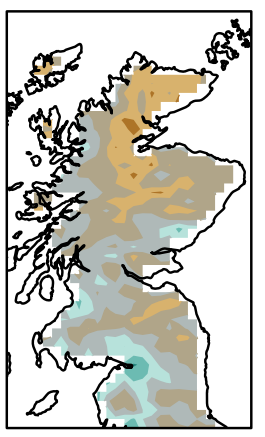

(j) FUT_12/PRES12: median $=1.35$
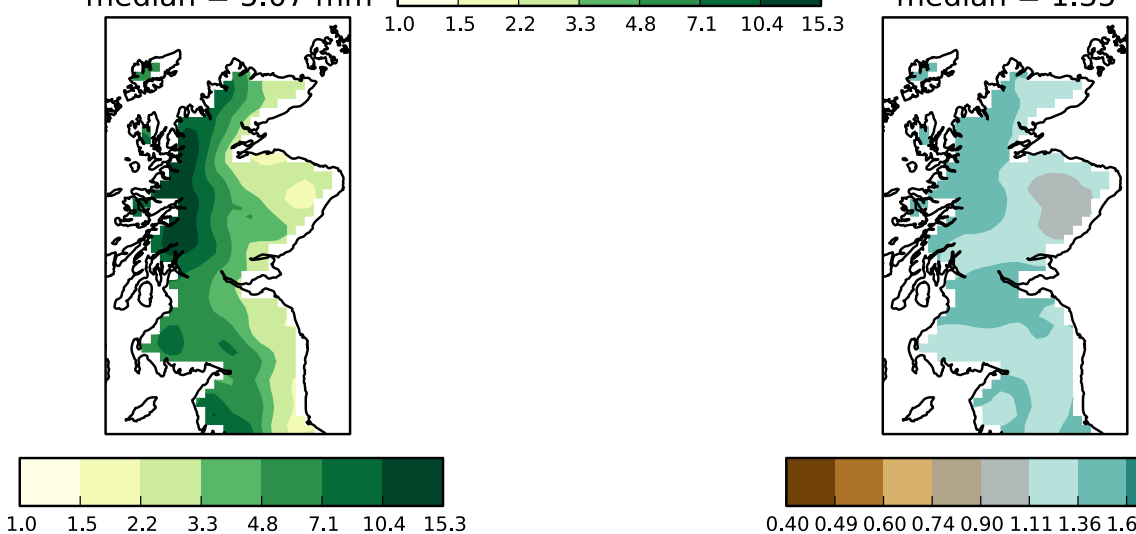

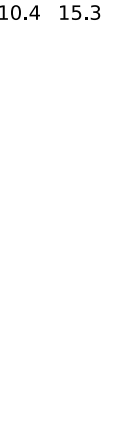


from the driving GCM. The driving GCM has similar precipitation biases (Supplementary Figures 3 and 4), which might be related to its storm track biases (Berthou et al. 2017). However, we find that biases for the $12 \mathrm{~km}$ hindcast simulation are quite similar to the GCM-driven simulation especially in winter (Supplementary Figure 5), suggesting structural biases of the $12 \mathrm{~km} \mathrm{RCM}$ are also a contributing factor; hence, the origin of these biases is hard to pinpoint, and is probably a combination of biases inherited from the driving GCM and structural biases of the RCM themselves.

While there is no $1.5 \mathrm{~km}$ hindcast simulation for comparison, the $1.5 \mathrm{~km}$ simulation domain is now known to be too small [Lock et al, personal communications], and that is likely to introduce additional structural biases to the $1.5 \mathrm{~km}$ simulations. Recent updates to the boundary layer scheme and the domain size in the current operational UK forecast model and the climate CPM (carried out after the SUK and NUK simulations were completed) improves significantly the problem of negative precipitation bias over the UK (Lock et al, personal communications).

\subsection{Future projections of mean daily precipitation}

A summer drying is projected for the whole northern UK domain (Fig. 2e), with many areas seeing a decrease of $25-50 \%$ in daily mean precipitation, including the relatively densely populated Scottish Central Lowlands, for both the 1.5 and $12 \mathrm{~km}$ simulations. This is similar to the drying found in the SUK simulation (Supplementary Fig. 1).

In contrast, the models predict higher precipitation for most regions in winter. The $1.5 \mathrm{~km}$ simulation shows a moderate increase of 10-35\% in parts of the Scottish Central Lowlands, western Scottish Highlands and the Lake District, and a 10-25\% decrease around Aberdeen. The $12 \mathrm{~km}$ simulation projections have a similar spatial pattern of change, but are slightly wetter. Winter SUK projections show a similar increase (Supplementary Fig. 2) with the largest increase over Wales.

\subsection{Frequency and intensity of hourly precipitation}

Mean precipitation biases and changes are a combination of changes in frequency and intensity. SUK projections have shown summer precipitation to generally get more intense but less frequent in the future (Chan et al. 2014a, 2016; Kendon et al. 2014), which leads to an overall decrease in that summer precipitation (Supplementary Fig. 1) yet intensification of extremes (Chan et al. 2014a; Kendon et al. 2014). The increase in return levels is smaller than the increase in extreme precipitation intensity because precipitation has become less frequent. Here we conduct a similar examination for the NUK simulations.

\subsubsection{Precipitation frequencies}

The frequencies for $1 \mathrm{~h}$ precipitation exceeding the $0.1 \mathrm{~mm} / \mathrm{h}$ "wet" threshold are shown in Figs. 4 and 5. For summer and winter, the Scottish Highlands have the highest frequency of wet hours in both models and in the observations. The 1.5 and $12 \mathrm{~km}$ simulations have opposite signed frequency biases during summer. The $1.5 \mathrm{~km}$ model produces precipitation too infrequently, mainly in the south of the domain, while the $12 \mathrm{~km}$ model produces precipitation too frequently, with largest positive biases over orography.

For winter in the present-climate simulations, the spatial medians of wet hour frequency for both 1.5 and $12 \mathrm{~km}$ model simulations are less than for observations, with large negative biases $(>50 \%)$ near to the west coast of Scotland in the $1.5 \mathrm{~km}$ simulation, and a small pocket of positive bias near to Dundee. This positive bias pocket might be due to radar observations inaccuracy, as this region is the furthest point from the three radar stations in Scotland: Aberdeen, Glasgow and Stornoway (Harrison et al. 2000). The $12 \mathrm{~km}$ DJF simulation agrees better with the radar observations apart from the eastern coast, where negative bias is large (25\% less frequent than radar).

Future projected summer wet hour frequency changes are dominated by a $30-60 \%$ decrease everywhere in both the $1.5 \mathrm{~km}$ and the $12 \mathrm{~km}$ simulations. Despite large terrain variation in NUK, the negative changes are fairly uniform. Similar levels of decrease were also found in the SUK simulation, and were attributed to circulation changes from the driving GCM (Chan et al. 2016).

In winter, future projections of the wet hour frequency in both the 12 and $1.5 \mathrm{~km}$ simulations show a clear west-east gradient, with an increase in frequency in the west and a decrease in the east. The magnitude of future change in wet hour frequency in the winter is smaller than in the summer.

\subsubsection{Precipitation intensities}

Histograms of precipitation intensities from radar observations and model simulations are presented in Figs. 6 (summer) and 7 (winter). In both seasons, present-day intensities between 0.1 and $1.0 \mathrm{~mm} / \mathrm{h}$ account for $\geq 50 \%$ of all wet hours, and intensities larger than $5 \mathrm{~mm} / \mathrm{h}$ are rare $(<2 \%$ for the $1.5 \mathrm{~km}$ simulation), which is a commonly found issue with PCMs (Trenberth et al. 2017). The $12 \mathrm{~km}$ fraction of wet hours with intensity $<1 \mathrm{~mm} / \mathrm{h}$ is larger than radar observations, compensated for by smaller fractions in higher intensity bins and lower skewness. The $1.5 \mathrm{~km}$ intensities, on the other hand, show more frequent heavy precipitation, especially in summer. Comparing results with Sect. 4.3.1, it is clear that reduced (increased) frequency of wet hours in the $1.5 \mathrm{~km}(12 \mathrm{~km})$ present-climate simulation are compensated by higher (lower) precipitation intensities. 
Fig. 4 Same as in Fig. 2, but for frequency of "wet" $(>0.1 \mathrm{~mm} / \mathrm{h})$ hours

\section{Frequency for precipitation larger than $0.1 \mathrm{~mm} / \mathrm{h}$ (Summer)}

(a) RCM1.5_PRESENT:

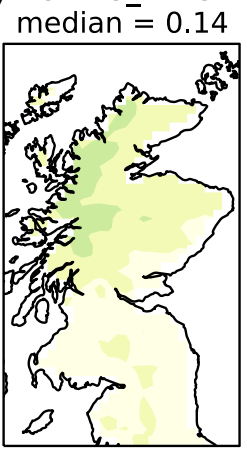

(d) RCM1.5_FUTURE_: median $=0.07$

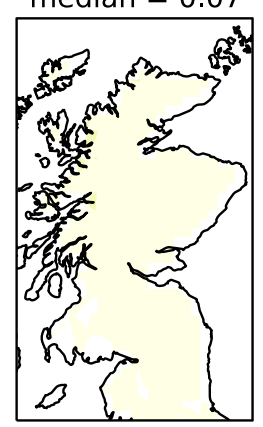

(f) RCM_PRESENT12: median $=0.22$

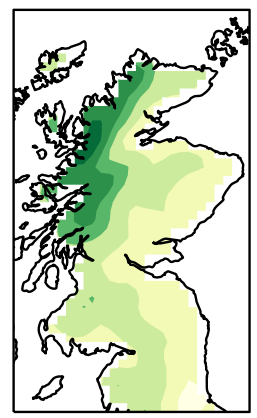

(i)

RCM_FUTURE 12: median $=0 . \overline{4}$
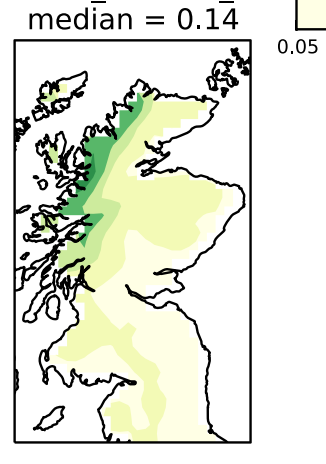

(b) oBs:

median $=0.17$

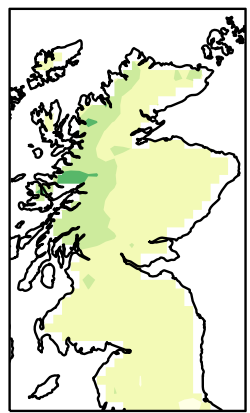

(g) OBS:

median $=0.17$

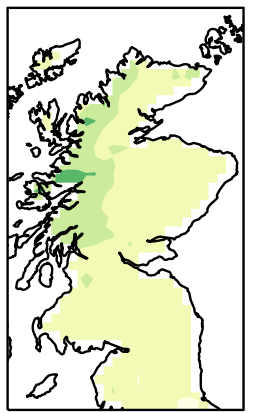

(j)

j) FUT 12/PRES12 :

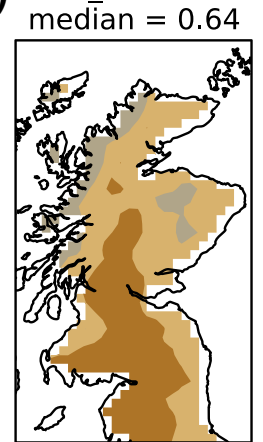

$\begin{array}{lllllllll}0.05 & 0.13 & 0.21 & 0.29 & 0.37 & 0.45 & 0.53 & 0.61\end{array}$

0.400 .490 .600 .740 .901 .111 .361 .662 .042 .50 
Fig. 5 Same as in Fig. 4, but for winter
Frequency for precipitation larger than $0.1 \mathrm{~mm} / \mathrm{h}$ (Winter)

(a) RCM1.5_PRESENT: median $=0.16$

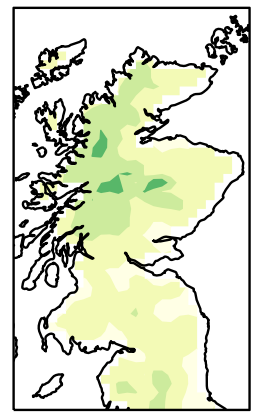

(d) RCM1.5_FUTURE_:

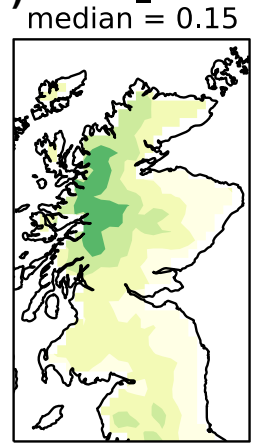

(f) RCM PRESENT12: median $=0.23$

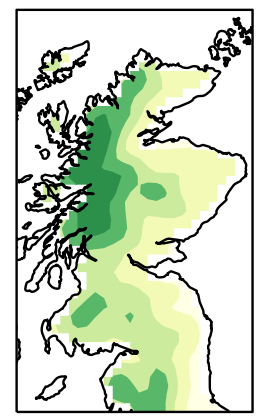

(i) RCM FUTURE 12 : median $=0 . \overline{6}$

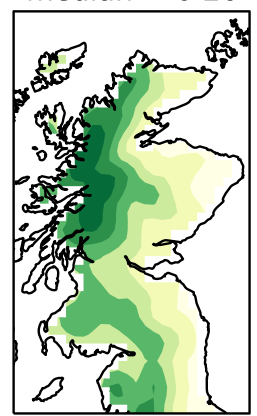

$\begin{array}{llllllll}0.05 & 0.13 & 0.21 & 0.29 & 0.37 & 0.45 & 0.53 & 0.61\end{array}$
(b)oBs:

median $=0.25$

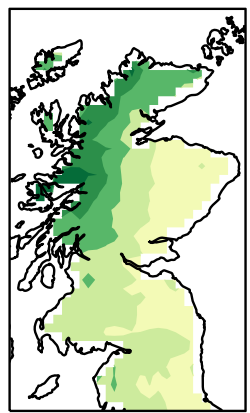

(g) OBS:

median $=0.25$
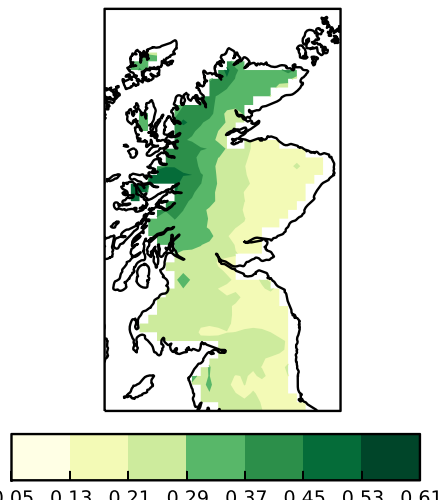

$\begin{array}{llllllll}0.05 & 0.13 & 0.21 & 0.29 & 0.37 & 0.45 & 0.53 & 0.61\end{array}$

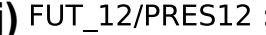

median $=1.13$

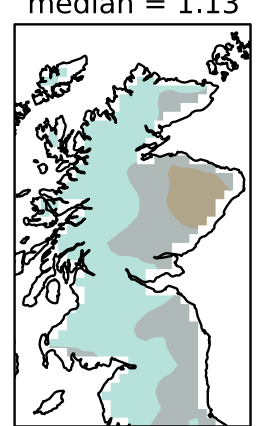

0.400 .490 .600 .740 .901 .111 .361 .662 .042 .50 
Fig. 6 Histogram of radar and $1.5 \mathrm{~km} / 12 \mathrm{~km}$ present- and future-climate model simulated intensity, excluding values below $0.1 \mathrm{~mm} / \mathrm{h}$. Only land points are included, and all individual values are pooled before binning. The skewnesses $\left(\gamma_{1}\right)$ of underlying data are given in the legend
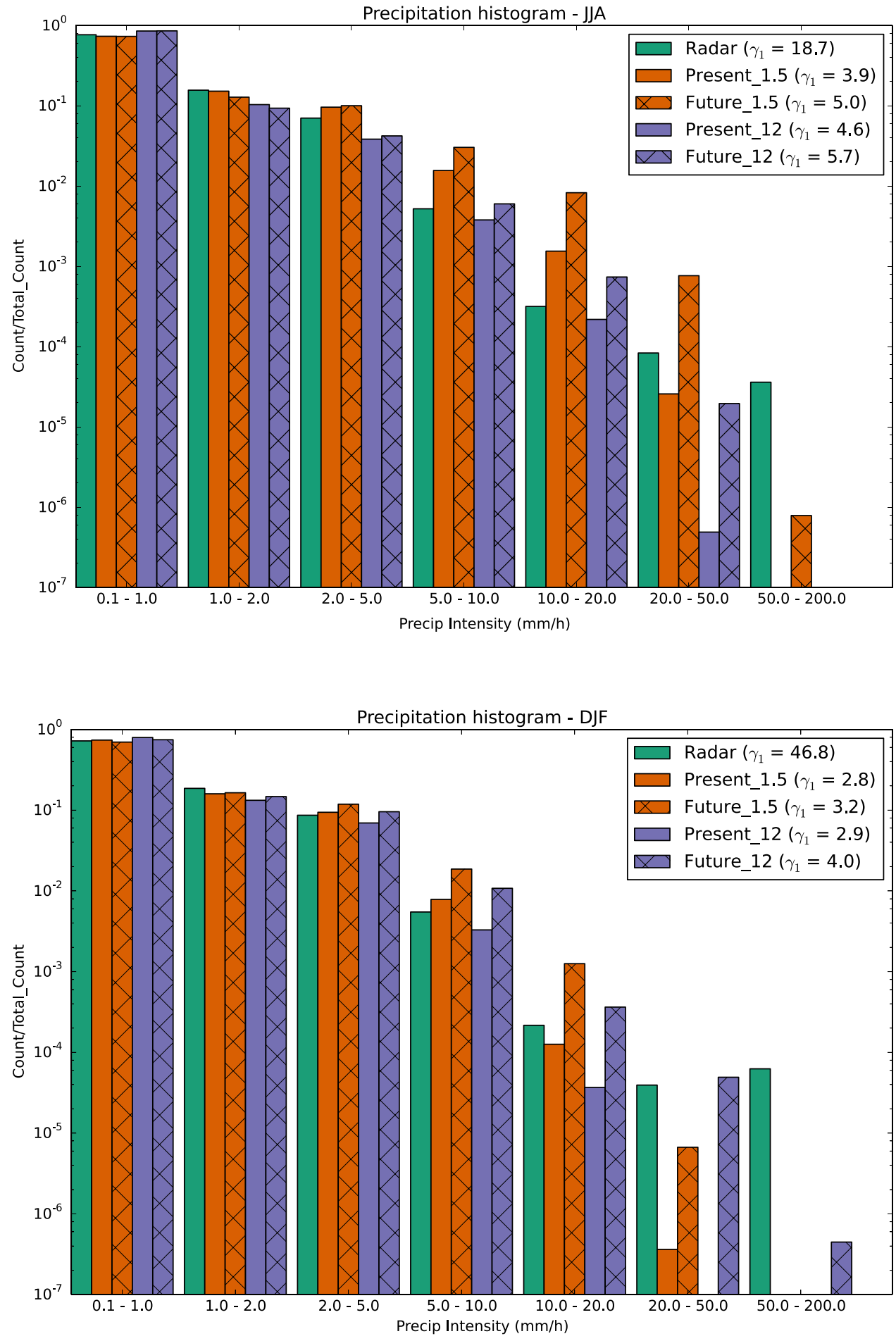

Fig. 7 Same as in Fig. 6, but for winter
Both models seem to underestimate the frequency of very high intensities $(>20 \mathrm{~mm} / \mathrm{h}$ ), but it is questionable if those high radar intensity readings are accurate and whether radar readings above $10 \mathrm{~mm} / \mathrm{h}$ are valid for model evaluation (e.g. the number of $50+\mathrm{mm} / \mathrm{h}$ counts in the winter radar data is 3 times larger than the number of $20-50 \mathrm{~mm} / \mathrm{h}$ counts). The skewnesses of the data are given in the legend of Figs. 6 and 7. JJA (DJF) radar skewness is more than 4 (16) times of the present-climate model data. Gauge observations in Scotland (Blenkinsop et al. 2017 ) have JJA and DJF mean skewnesses of $\approx 4.6$ and 4.5 , respectively (Lewis, 200 personal communications), which are much more consistent with the RCM estimates. 
Table 1 Average "wet hour" ( $\geq 1 \mathrm{~mm} / \mathrm{h}$ ) intensity for radar observations, 1.5 and $12 \mathrm{~km}$ simulations. Model-simulated future-divided-by-present changes $(\mathrm{F} / \mathrm{P})$ are also given

\begin{tabular}{|c|c|c|c|c|c|c|c|}
\hline Season & Radar mm/h & 1.5 present $\mathrm{mm} / \mathrm{h}$ & 1.5 future $\mathrm{mm} / \mathrm{h}$ & F/P & 12 present $\mathrm{mm} / \mathrm{h}$ & 12 future $\mathrm{mm} / \mathrm{h}$ & $\mathrm{F} / \mathrm{P}$ \\
\hline JJA & 0.756 & 0.895 & 1.076 & 1.20 & 0.573 & 0.578 & 1.01 \\
\hline DJF & 0.864 & 0.828 & 0.985 & 1.19 & 0.685 & 0.838 & 1.22 \\
\hline
\end{tabular}

Fig. 8 Diurnal cycle of summer mean hourly precipitation, taken as the spatial median over the entire domain. Only land points are included. Time zone is in UTC "zulu” time (UK local winter time)

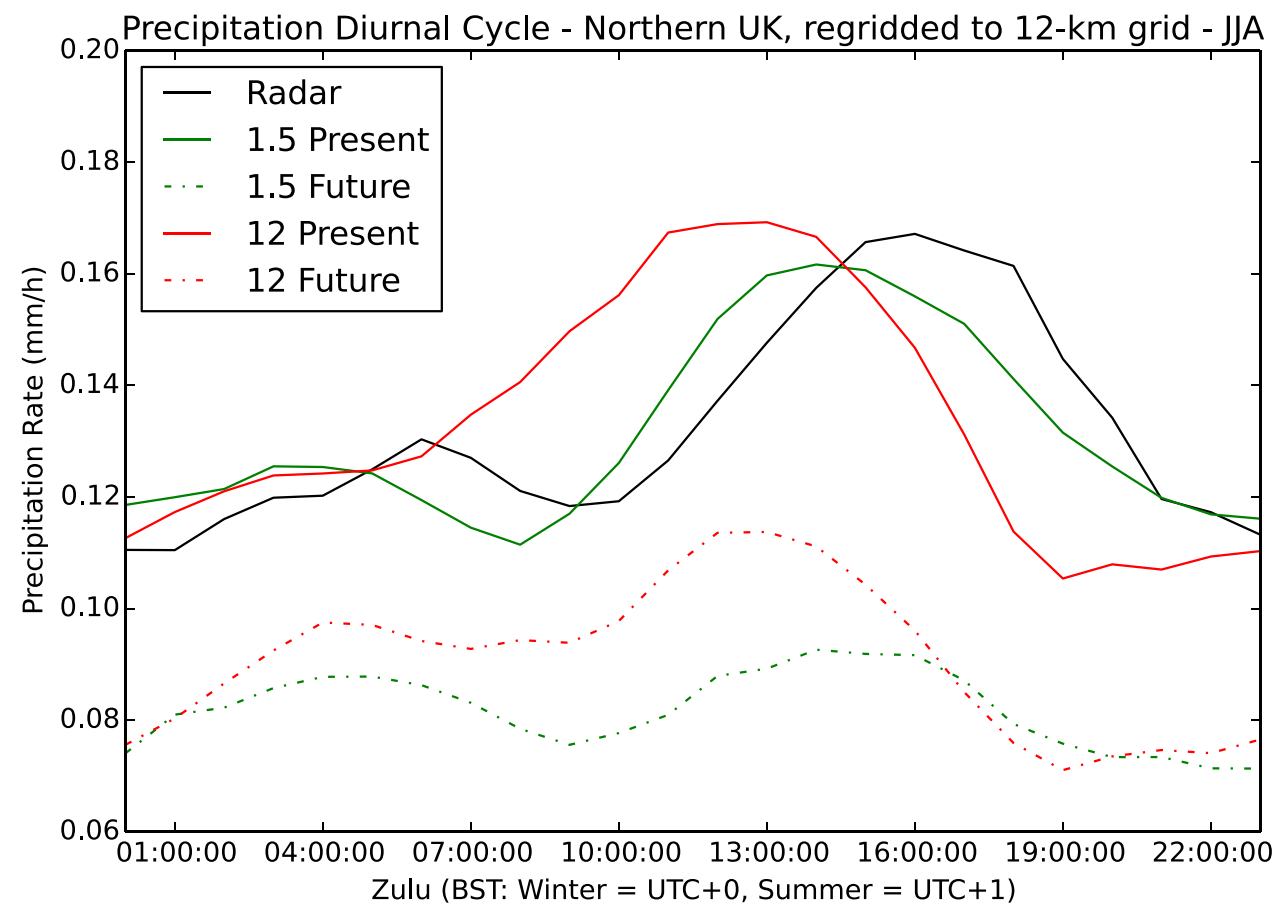

In future, precipitation intensities increase in both summer and winter for both 1.5 and $12 \mathrm{~km}$ simulations. There is an increase of frequency in wet hours for all bins higher than $2 \mathrm{~mm} / \mathrm{h}$, and this leads to increased positive skewness for both summer and winter. For example, the $1.5 \mathrm{~km}$ simulation sees a 20 -fold increase in the $20-50 \mathrm{~mm} / \mathrm{h}$ bin for summer and winter.

The changes in the mean wet hour intensity for the 1.5 and $12 \mathrm{~km}$ simulations are given in Table 1 . The overall mean changes for $1.5 \mathrm{~km}$ precipitation intensity for both summer and winter are about $20 \%$, which contrasts the very large changes in the high intensities as shown in Figs. 6 and 7. Tail extreme intensities are too rare to have significant impact on the mean intensity changes as they account for no more than $1 \%$ of the "wet" hours, but they are an important feature of future projections with potentially strong impacts, and are reflected in the return level changes (Sect. 4.5). Mean intensity changes are dominated by changes to bins below $5 \mathrm{~mm} / \mathrm{h}$ with increased frequencies of $2-5 \mathrm{~mm} / \mathrm{h}$ events in both summer and winter and decreased frequencies for the lower intensities. The $20 \%$ mean increase in summer intensity for the $1.5 \mathrm{~km}$ simulations is outweighed by $50-60 \%$ decrease in overall precipitation frequency. Therefore, while the future mean precipitation decreases, extremes still intensify.

\subsection{Diurnal cycle}

Differences in diurnal cycle are often used to distinguish CPMs from PCMs (Clark et al. 2016; Lean et al. 2008). Convection parameterisations in PCMs do not represent the development and decay of convection properly, and so the diurnal cycle representation is notably worse than CPMs (Ban et al. 2014; Keller et al. 2016; Kendon et al. 2012; Prein et al. 2013). The radar-observed and modelsimulated summer diurnal cycles are shown in Fig. 8. Radar observations indicate the diurnal maximum occurs in the late afternoon around $16 \mathrm{Z}$, which is consistent with in situ observations in Scotland (Svensson and Jakob 2002). Both 1.5 and $12 \mathrm{~km}$ present-climate simulations have diurnal peaks earlier than observed, but the timing of the peak is better for the $1.5 \mathrm{~km}$ simulation. Similar early diurnal peaking of precipitation is found in ETHZürich CPM simulations over the Alps (Keller et al. 2016; Leutwyler et al. 2017). This early peaking bias is not found 
Fig. 9 Same as in Fig. 8 but for winter

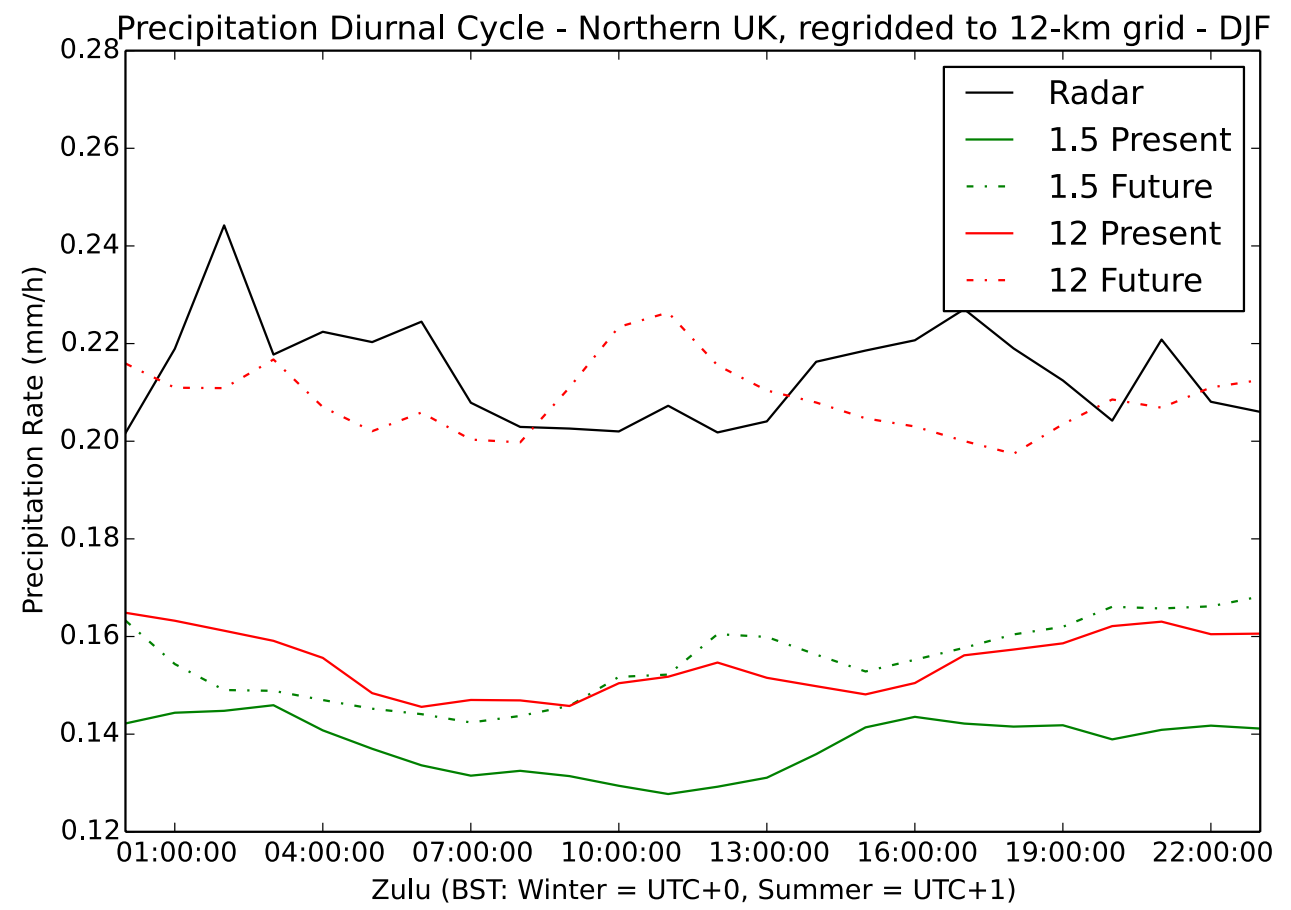

in the southern UK simulations (Kendon et al. 2012), possibly due to the absence of steep orography. Future rates are lower in summer as expected from the projected decrease in mean precipitation (Fig. 2), and the diurnal cycle shows a similar early peak. JJA diurnal cycles for both future simulations are flatter than the present-climate simulations, and the diurnal decrease is slightly higher in fractional terms during the afternoon hours relative to the morning and overnight hours (see Supplementary Fig. 6).

What causes the summer diurnal cycle biases? Precipitation in Scotland is highest over orography (Fig. 2). A simple separation of the $1.5 \mathrm{~km}$ model-simulated summer diurnal cycle by surface height (Supplementary Fig. 7) does not appear to separate areas with and without the diurnal cycle bias, suggesting a complex cause to the diurnal cycle bias. NUK precipitation is generally more stratiform than SUK, partially due to its orography but also due to higher synoptic variability in NUK. The model separation and interaction between stratiform and convective precipitation may differ from reality. Diurnal biases in temperature and differential heating over orography may also contribute to the diurnal precipitation biases due to their roles in local up-slope winds.

The winter diurnal cycles are shown in Fig. 9. Neither the radar-observations nor the model simulations show a clear daily peak in winter precipitation. However, the hourly range from the radar observations is $\approx 0.04 \mathrm{~mm} / \mathrm{h}$ (or $\approx 18 \%$ of the diurnal mean), which is more than double the simulated range $(\approx 0.01 \mathrm{~mm} / \mathrm{h}$ or $\approx 6-8 \%$ of the diurnal mean).

\subsection{Return level projections}

Return levels for "short" return periods are more robust as they are sampled by more data and do not rely on extrapolation. As our simulations are just slightly longer than a decade, any return periods beyond 10 years are extrapolations. Previous results for the SUK have indicated an increase of both summer and winter extreme return levels (Chan et al. 2014a). The relatively robust 5 -year summer and winter return levels $z(5)$ and their changes for $1 \mathrm{~h}$ and 1 day precipitation for the 1.5 and $12 \mathrm{~km}$ northern UK simulations are shown in Figs. 10, 11, 12, 13. We also present $z(5)$ estimates from radar observations (for $1 \mathrm{~h}$ precipitation) and UK5 (for 1 day precipitation) as well. Note, however, the radar data quality control issues discussed earlier.

\subsection{1 z(5): 5-year return level changes}

The $1 \mathrm{~h}$ summer $z(5)$ for both present-day and end-of-21stcentury simulations have no clear spatial pattern; there is no clear distinction between lowlands and orography. For the observations, the higher $z(5)$ tends to be in the southern 2 / 3 of the domain. Winter 5-year return levels, however, are larger over orography for both hourly (Fig. 11) and daily (Fig. 13) precipitation.

Future $1 \mathrm{~h} z(5) \mathrm{s}$ have risen in both summer and winter and for both 1.5 and $12 \mathrm{~km}$ simulations. The $1.5 \mathrm{~km}$ model's median values have risen by more than $40 \%$ in both seasons. The summer increase is larger then the SUK return level projections $(\approx 10 \%$; Chan et al. $2014 \mathrm{a}$ ), and is in contrast 


\section{0-yr return levels $Z(5.0)$ for hourly precipitation (Summer)}
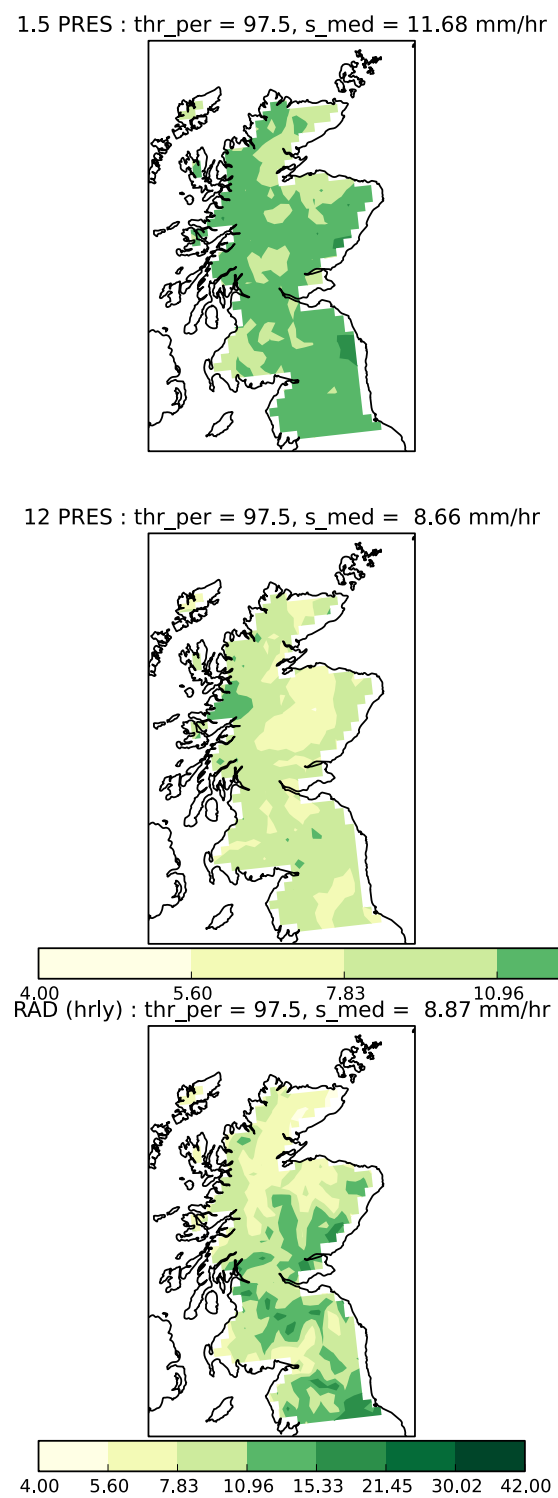

Fig. 10 Maps of 5-year return level $z(5)$ values for summer $1 \mathrm{~h}$ precipitation $(\mathrm{mm} / \mathrm{h})$ - left column: present-climate simulations and radar; middle column: future simulations. The projected fractional

with the projected decline in mean summer precipitation. The $12 \mathrm{~km}$ simulations show a similar increase for the winter $1 \mathrm{~h} \mathrm{z}(5)$ as the $1.5 \mathrm{~km}$ simulations, but the simulated summer increase is smaller $(\approx 20 \%)$.

For both summer and winter, the largest model-simulated 1 day $z(5)$ s are over the western windward side of the Scottish Highlands, which faces the mid-latitude westerlies and Atlantic Ocean, and seem to be dominated by orographic precipitation. The observed daily $\mathrm{z}(5)$ shows a clear pattern of higher values over orography (Figs. 12 and 13, bottom panels), which is captured by the models reasonably well. changes are given in the right column. Upper, middle and lower rows are for $1.5 \mathrm{~km} \mathrm{CPM}, 12 \mathrm{~km} \mathrm{RCM}$, and radar observations

The 1 day $z(5) \mathrm{s}$ for the $1.5 \mathrm{~km}$ simulations are somewhat higher than both the observations and the $12 \mathrm{~km}$ simulation.

Future 1 day $\mathrm{z}(5) \mathrm{s}$ have risen in both summer and winter and for both models (Figs. 12 and 13), with median values over the entire domain risen by $\approx 0-35 \%$. This is a somewhat smaller increase then for the $1 \mathrm{~h} \mathrm{z}(5)(\approx 20-50 \%)$. For summer, the largest 1 day $\mathrm{z}(5)$ rises for the $1.5 \mathrm{~km}$ simulations are in the Lake District and the western half of Scotland. There are no clear spatial change patterns for the $12 \mathrm{~km}$ simulations nor for the winter 1 day $z(5) \mathrm{s}$; localised decreases are mostly concentrated in the eastern half of Scotland. 
5.0-yr return levels $Z(5.0)$ for hourly precipitation (Winter)

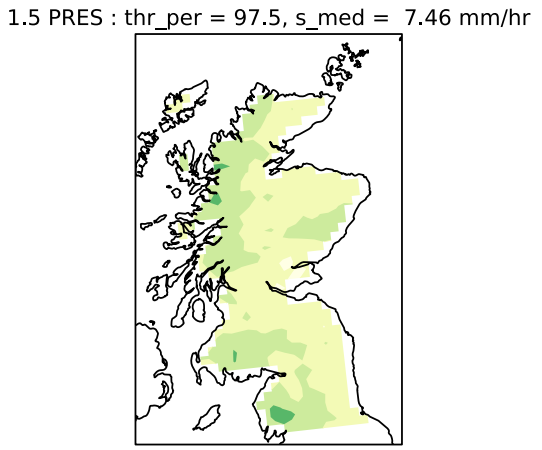

12 PRES : thr per $=97.5, \mathrm{~s}$ med $=6.47 \mathrm{~mm} / \mathrm{hr}$

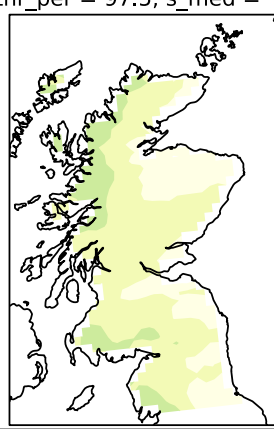

RAD (hrly) : thr_per $=97.5, \mathrm{~s}_{\text {_.med }}^{7.83}=8.12 \mathrm{~mm} / \mathrm{m} / \mathrm{hr}$
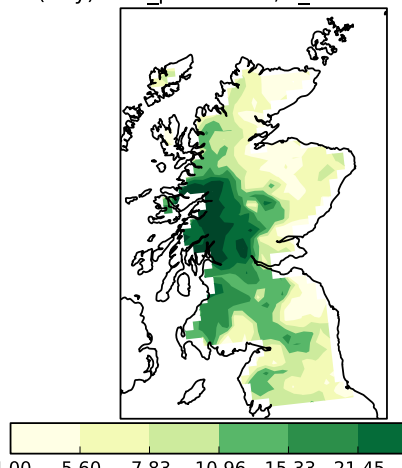

\begin{tabular}{lrrrrrrr}
\hline 4.00 & 5.60 & 7.83 & 10.96 & 15.33 & 21.45 & 30.02 & 42.00
\end{tabular}

Fig. 11 Same as in Fig. 10 but for winter

\subsubsection{Across return periods}

Both observed and model-simulated summer and winter spatial median return levels for return periods between 2and 30-years are shown in Figs. 14 and 15. For summer, the $1.5 \mathrm{~km}$ present-climate simulation has higher $1 \mathrm{~h}$ and 1 day return levels than observations and $12 \mathrm{~km}$ simulations, which is consistent with our previous understanding of positive intensity biases from the $1.5 \mathrm{~km}$ model (Kendon et al. 2012). The differences in winter $1 \mathrm{~h}$ return levels between the 1.5 and $12 \mathrm{~km}$ simulations are small relative to their differences with radar observations. Radar $z(5) s$ are higher than both 1.5 and $12 \mathrm{~km}$ simulations for all examined return periods.
The future return levels for summer are higher (shown as percentage change in Fig. 14, bottom panels). They increase with return period, suggesting higher intensification for rarer extremes. Return level intensifications are higher in the $1.5 \mathrm{~km}$ simulations than the $12 \mathrm{~km}$ simulations. For shorter return periods (e.g. $<5$ years), the $12 \mathrm{~km}$ simulations show little return level changes for 1 day precipitation. The $1.5 \mathrm{~km}$ simulations project a $50 \%$ increase for $z(30)$; this is nearly five times higher than the $\approx 10 \%$ increase for southern UK simulations (Chan et al. 2014a).

In winter, the 1 day return levels for both 12 and $1.5 \mathrm{~km}$ current-climate simulation return levels agree with observations. For $1 \mathrm{~h}$ return levels, radar-estimated return 
5.0-yr return levels $Z(5.0)$ for daily precipitation (Summer)

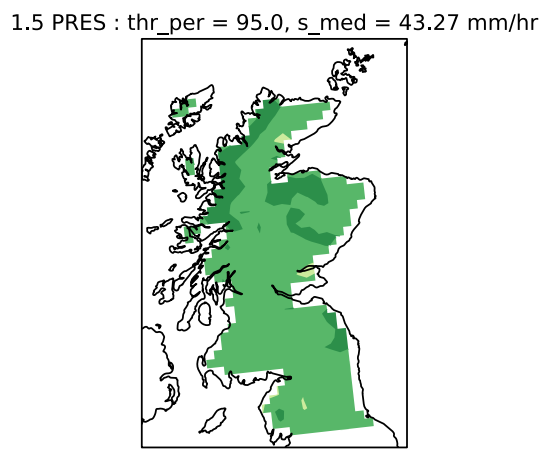

12 PRES : thr per $=95.0, \mathrm{~s}$ med $=36.40 \mathrm{~mm} / \mathrm{hr}$

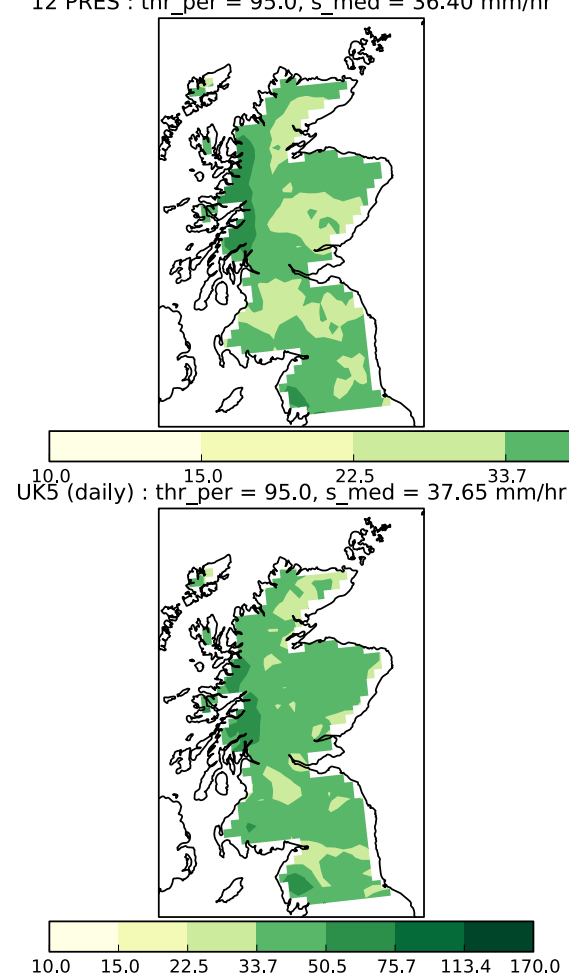

1.5 FUT_ : thr_per $=95.0$, s_med $=50.86 \mathrm{~mm} / \mathrm{hr}$

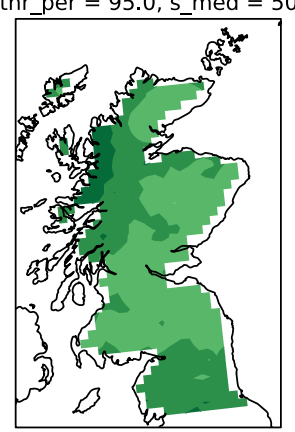

12 FUT_ : thr_per $=95.0$, s_med $=36.23 \mathrm{~mm} / \mathrm{hr}$

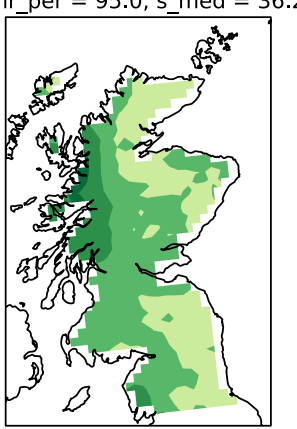

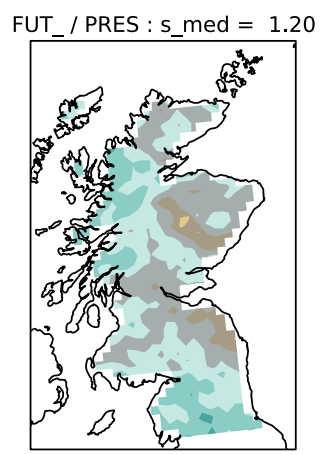

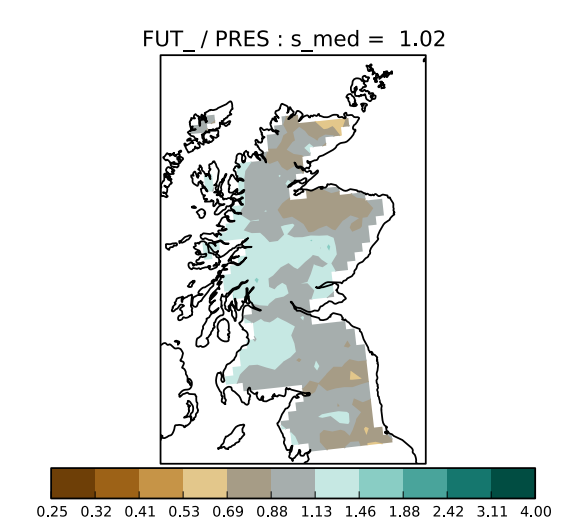

Fig. 12 Same as in Fig. 10 but for 1 day precipitation (mm/day). Instead of radar, UK5 observations are used for the bottom row

levels diverge from both model estimates as return period increases; given the questionable quantification of winter hourly extremes (Sect. 4.3.2), this divergence is likely to be spurious. The percentage changes for winter return levels (Fig. 15, bottom panels) for all examined return periods are positive, and the $12 \mathrm{~km}$ simulations show consistently higher projected percentage increase. For both models, the percentage changes for $1 \mathrm{~h}$ return level increase from $40 \%$ to $50-60 \%$ as return periods increase from 2 to 30 years; comparable percentage changes were also found for the southern UK simulations (Chan et al. 2014a). Percentage increases for 1 day return levels are more moderate (20-40
$\%)$ than the $1 \mathrm{~h}$ return level changes, and are lower than the southern UK projections $(\approx 40-70 \%)$ (Chan et al. 2014a).

The SUK 1.5 and $12 \mathrm{~km}$ simulations show an increase in winter return levels, but the $12 \mathrm{~km}$ simulations show a decrease in summer (Chan et al. 2014a). In the NUK, we see an increase in both models in winter and summer except for the shortest return periods ( $<3$ years) for daily extreme precipitation. The actual projections still differ significantly between the two models; for instance, projected summer increase for $1 \mathrm{~h}$ precipitation return levels are two times higher in the $1.5 \mathrm{~km}$ simulations. 
5.0-yr return levels $Z(5.0)$ for daily precipitation (Winter)
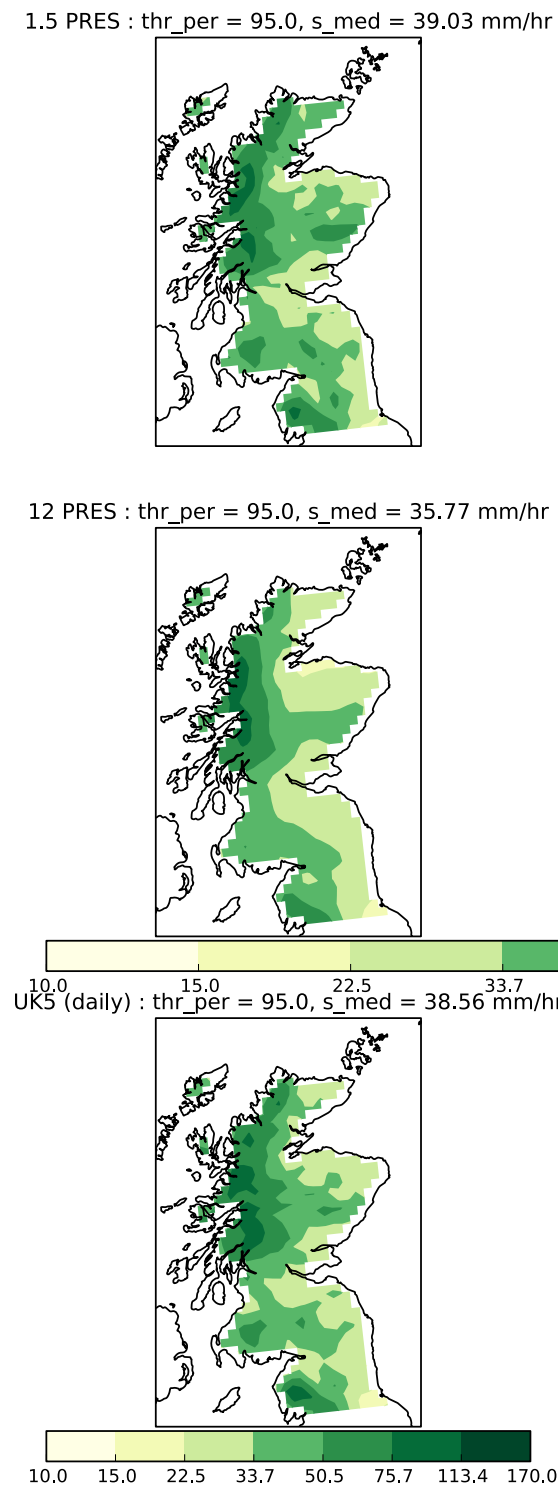

Fig. 13 Same as in Fig. 12 but for winter

\section{Discussion and conclusions}

We have assessed the present day state and future projections for the mean and extreme precipitation as simulated by a pair of GCM-driven 12 and $1.5 \mathrm{~km}$ UKMO RCM simulations for NUK. The two models show a different spatial pattern in mean precipitation bias, both in summer and winter, suggesting different underlying causes of the bias-the $12 \mathrm{~km}$ model has mean biases that are caused by the driving GCM plus factors inherent to the $12 \mathrm{~km}$ model, while the $1.5 \mathrm{~km}$ model has additional biases due to the setup of the $1.5 \mathrm{~km}$ simulation domain and model physics.
For the $12 \mathrm{~km}$ simulation biases, one was tempted to trivially link them to the driving GCM biases, but a comparison with the hindcast simulation suggested a more complex origin. The $1.5 \mathrm{~km}$ domain size issue is now addressed for the current UK operational and upcoming UKCP18 CPM simulations by using a larger simulation domain. The general consensus for optimal domain size is to be neither too "large (so the simulation does not diverge strongly from the driving dataset on the large-scale) nor too "small" (so that small-scale features are given time to develop) (Leduc and Laprise 2009; Leduc et al. 2011). However, what is too "large" or too "small" are often model and 

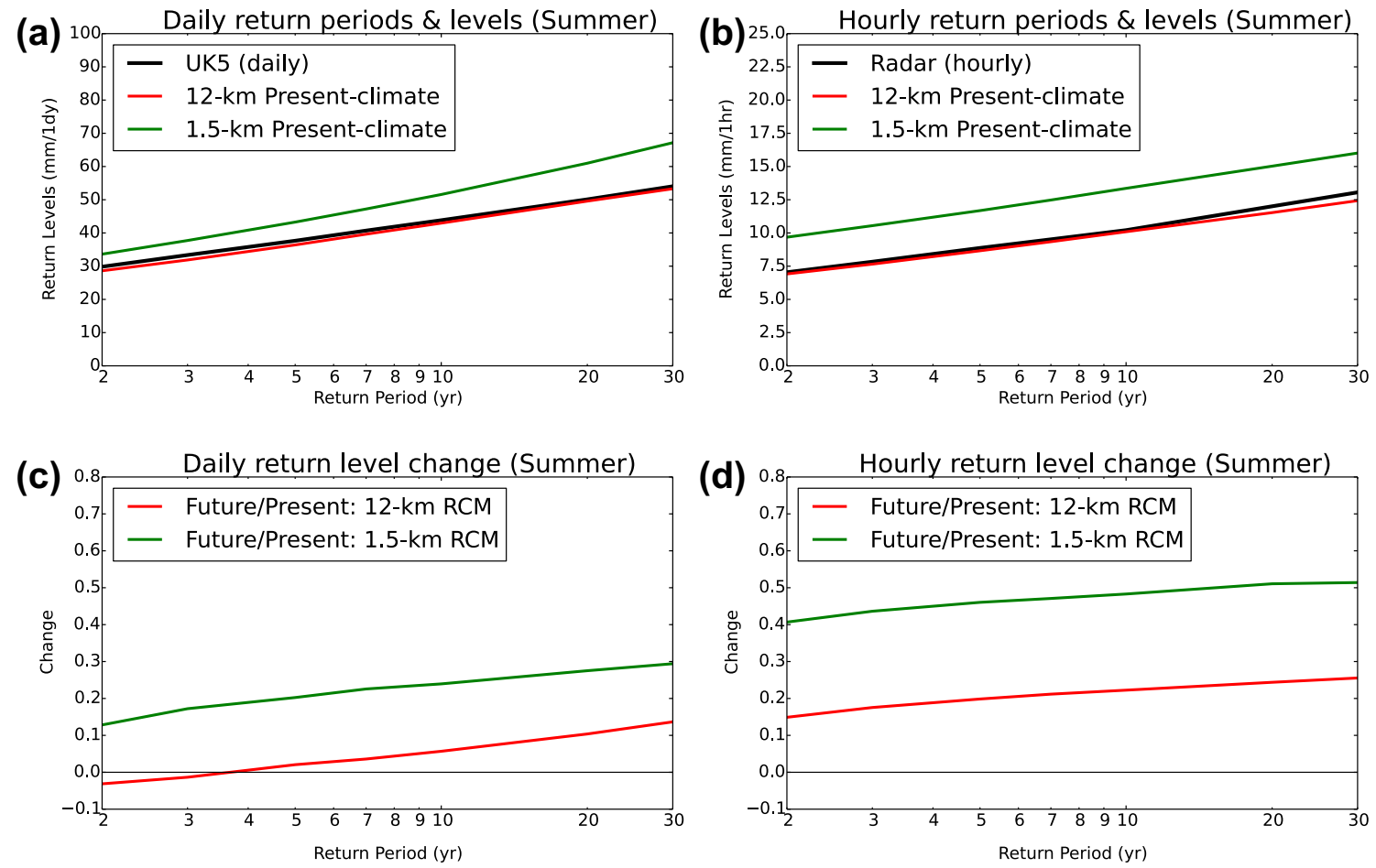

Fig. 14 Spatial summary of the summer return levels and their projected change for NUK for return periods between 2 and 30 years. Left panels show the 1 day extreme return levels, and right panels show the $1 \mathrm{~h}$ extreme return levels. For the upper panels, the black,

red, and green are for observations, $12 \mathrm{~km}$ and $1.5 \mathrm{~km}$ present-climate simulations, respectively. Bottom panels are the projected change $\left(\frac{\text { Future }}{\text { Present }}-1\right)$ for the $12 \mathrm{~km}$ (red) and $1.5 \mathrm{~km}$ (green) simulations
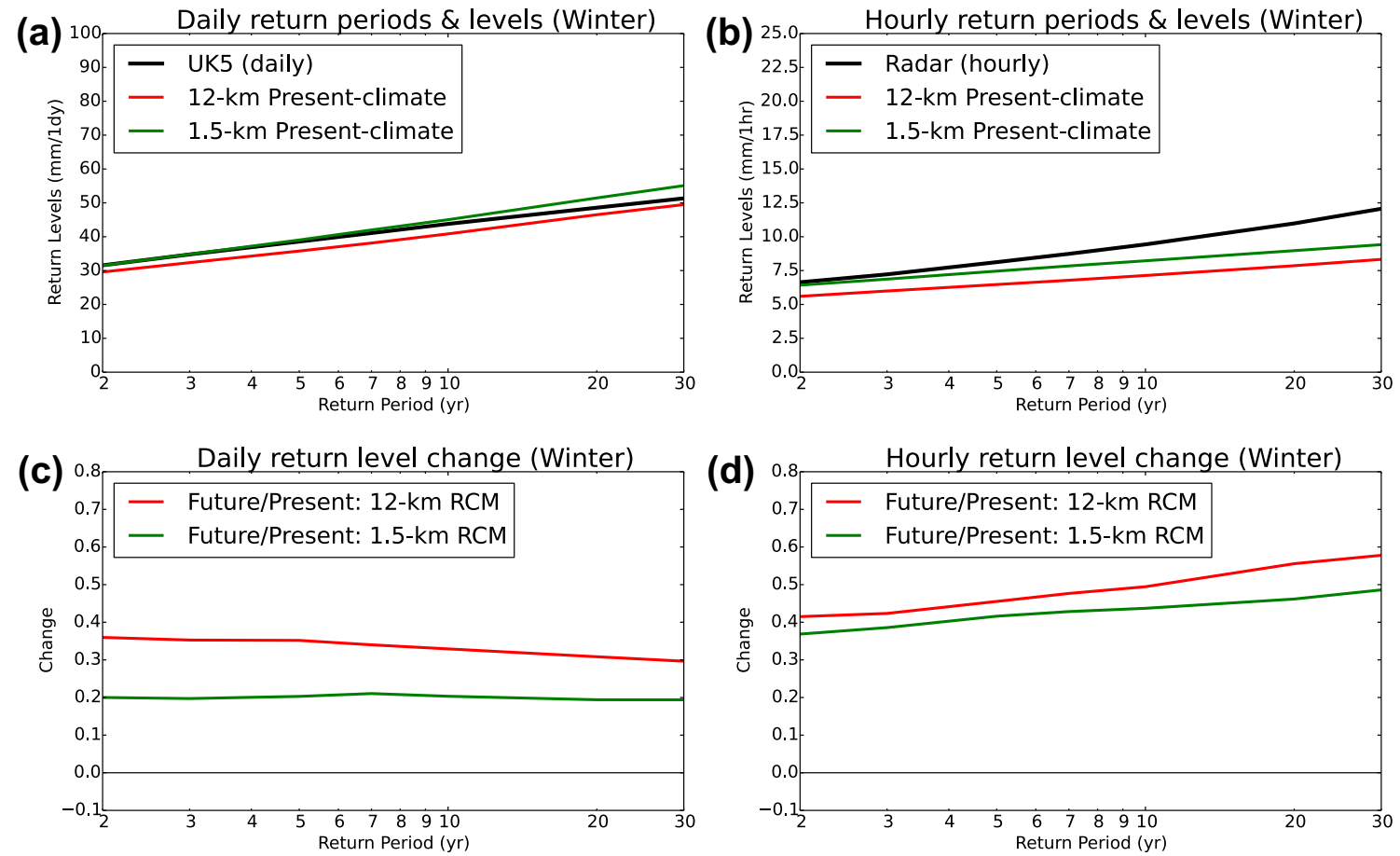

Fig. 15 Same as in Fig. 14, but for winter 
regional circulation dependent (Leduc and Laprise 2009; Matte et al. 2017). The best domain sizes are generally found by conducting large number of simulations with different domains.

Despite the above, differences between the 12 and $1.5 \mathrm{~km}$ simulations in frequency of precipitation and diurnal cycle are more consistent with previous results from the southern UK results and other simulation domains (Keller et al. 2016; Kendon et al. 2012); this includes the general tendency of the CPM simulations to precipitate less often but at higher intensity with better diurnal timing than lower-resolution PCM simulations. Higher resolution models have other benefits such as resolving of complex topography. Only the $1.5 \mathrm{~km}$ model resolves local precipitation maxima and minima in the Scottish Highlands and the Lake District (see Fig. 3b); the latter is critical for project NUTCAT2050 in which local rivers around the Lake District are a major focus.

Despite differences in mean precipitation biases, the future projections of precipitation change for NUK are very similar for both models. Both models predict a precipitation increase in winter and large summer decrease (30-50\%). It is only at the tail of the probability distribution that the two simulations differ from each other with a larger extreme $1 \mathrm{~h}$ rainfall intensification in the $1.5 \mathrm{~km}$ model in summer. Both models agree, however, on the direction of change and the projected intensification is larger than for the SUK. In winter, the mean and extreme precipitation changes are largely similar between the two simulations. Due to different physical representations of precipitation between CPMs and PCMs, one may expect their projections to differ the mostly in the warm seasons.

Results here show that extreme intensity changes are much higher than the mean intensity change. In particular, the mean hourly intensity increases are typically no higher than $20 \%$ in both models (Table 1), whilst the probabilities for $20.0+\mathrm{mm} / \mathrm{h}$ events have increased by more than an order of magnitude in both models. This higher extreme change may be related to their higher thermodynamic sensitivity to temperature changes (Trenberth et al. 2003), and can lead to large probability changes for extreme precipitation (Neelin et al. 2017).

Summer mean precipitation decreases for all models due to large decreases in precipitation frequency, but their extremes all intensify. This is a well-known result from many previous theoretical and modelling studies (for instance: Neelin et al. 2017; Pall et al. 2007), and highlights the importance of treating extreme changes and mean changes separately. This is also important from a climate impact perspective; for instance, results here may suggest drier summers with more frequent flash flooding, which might have an effect on soil erosion, agriculture practices, and stream water quality.
Substantial doubts are raised regarding the reliability of high-intensity $(10+\mathrm{mm} / \mathrm{h}) 1 \mathrm{~h}$ radar precipitation. While radar observations are found to be adequate and suitable for extreme precipitation assessments in SUK (Chan et al. 2014b), this might not be the case for NUK where radar coverage is poorer. However, radar data are perhaps good enough for diurnal cycle analysis as the daily and diurnal means are mostly controlled by the frequency of dry hours and low intensity precipitation (Figs. 3 and 7). Errors in the tail are most clear when their skewness and return levels are diagnosed. The winter hourly precipitation values in both models are markedly smaller then the radar values (by $25 \%$, Fig. 9), but show a much smaller negative bias when compared with UK5 rain gauge data ( $15 \%$, Fig. 3). This highlights the uncertainty in the observations currently available to evaluate the models, even in the UK which has a well developed observation system, and demonstrates the need for high-quality high-density observation system required to support modelling studies like this.

In summer when radar data are more reliable, the $1.5 \mathrm{~km}$ diurnal cycle compares better with radar data than the $12 \mathrm{~km}$ simulation. A good diurnal cycle is indicative that convective processes are well captured, and hence gives us more confidence in the $1.5 \mathrm{~km}$ CPM projections for convective extremes. However, there is still a discrepancy in the timing of maximum and minimum daily rainfall, which is still found in newer CPM simulations (Keller et al. 2016; Leutwyler et al. 2017).

The results presented here are limited by the fact that there is no $1.5-\mathrm{km}$ northern UK hindcast simulation. However, the Met Office has already planned new reanalysisand GCM-driven (convection-permitting) regional climate simulations over the UK (UKCP 2017). A direct comparison between reanalysis- and GCM-driven CPM simulations will become possible in the near future.

These simulations are essential benchmarks for future model simulations. Since the introduction of the convection-permitting model for weather forecasting and climate research, many new updates have been introduced to the model to address issues arising from operational and climate applications. However, there are still many challenges that are far from resolved, and they are not limited to the diurnal cycle problem that is mentioned here, for example: greyzone turbulence (Honnert 2016; Prein et al. 2015), proneness to errors from driving data (Leduc and Laprise 2009). Finding and addressing these model issues are challenging as observations may also be prone to large errors; hence it is critical to document model and observation biases for the benefit of the wider modelling community. Despite the above issues, the intensification of extreme precipitation and reduction of summer mean precipitation found here is consistent with previous results and seems to be robust, along with the finding that extreme precipitation changes 
may differ significantly between CPMs and PCMs (Chan et al. 2014b), even if their mean precipitation projections are similar.

Acknowledgements This research is part of the projects NUTCAT2050, CONVEX, INTENSE, and UKMO Hadley Centre research programme, which are supported by the United Kingdom NERC Changing Water Cycle programme (NUTCAT2050 and CONVEX; Grants NE/K002392/1, NE/K002430/1, NE/K002406/1 and NE/ I006680/1), European Research Council (INTENSE; Grant ERC-2013CoG-617329), and the Joint Department of Energy and Climate Change and Department for Environment Food and Rural Affairs (UKMO Hadley Centre research programme; Grant GA01101), respectively. Hayley J. Fowler is also funded by the Wolfson Foundation and the Royal Society as a Royal Society Wolfson Research Merit Award (WM140025) holder. Large portions of the analysis have been carried out with the free-and-open-source software R and Python. Fig. 1 uses GIS information provided by Natural Earth (http://www.naturalearthdata.com). Model data are available upon request from the UK Met Office. Data fees may apply.

Open Access This article is distributed under the terms of the Creative Commons Attribution 4.0 International License (http://creativeco mmons.org/licenses/by/4.0/), which permits unrestricted use, distribution, and reproduction in any medium, provided you give appropriate credit to the original author(s) and the source, provide a link to the Creative Commons license, and indicate if changes were made.

\section{References}

Ban N, Schmidli J, Schär C (2014) Evaluation of the convectionresolving regional climate modeling approach in decade-long simulations. J Geophys Res 119(13):7889-7907. https://doi. org/10.1002/2014JD021478

Berthou S, Chan SC, Kendon EJ, Roberts MJ, Lee RW, Vannière B (2017) Do high-resolution convection-permitting experiments on Europe need to be driven by high resolution global runs? In: European geophysical union general assembly 2017, Vienna, Austria, http://presentations.copernicus.org/EGU2017-18681_presentati on.pdf

Blenkinsop S, Lewis E, Chan SC, Fowler HJ (2017) Quality control of an hourly rainfall dataset and climatology of extremes for the UK. Int J Climatol 37(2):722-740. https://doi.org/10.1002/joc.4735

Chan SC, Kendon EJ, Fowler HJ, Blenkinsop S, Ferro CAT, Stephenson DB (2013) Does increasing the spatial resolution of a regional climate model improve the simulated daily precipitation? Clim Dyn 41(5):1475-1495. https://doi.org/10.1007/s0038 2-012-1568-9

Chan SC, Kendon EJ, Fowler HJ, Blenkinsop S, Roberts NM (2014a) Projected increases in summer and winter UK sub-daily precipitation extremes from high resolution regional climate models. Environ Res Lett 9(084):019. https://doi.org/10.1088/17489326/9/8/084019

Chan SC, Kendon EJ, Fowler HJ, Blenkinsop S, Roberts NM, Ferro CAT (2014b) The value of high-resolution met office regional climate models in the simulation of multi-hourly precipitation extremes. J Clim 27(16):6155-6174. https://doi.org/10.1175/ JCLI-D-13-00723.1

Chan SC, Kendon EJ, Roberts NM, Fowler HJ, Blenkinsop S (2016) Downturn in scaling of UK extreme rainfall with temperature for future hottest days. Nat Geosci 9:24-28. https://doi.org/10.1038/ NGEO2596
Clark P, Roberts N, Lean H, Ballard SP, Charlton-Perez C (2016) Convection-permitting models: a step-change in rainfall forecasting. Meteorol Appl 23:165-181. https://doi.org/10.1002/met.1538

Coles S (2001) An introduction to statistical modeling of extreme values. Springer, London

Dee DP, Uppala SM, Simmons AJ, Berrisford P, Poli P, Kobayashi S, Andrae U, Balmaseda MA, Balsamo G, Bauer P, Bechtold P, Beljaars ACM, van de Berg L, Bidlot J, Bormann N, Delsol C, Dragani R, Fuentes M, Geer AJ, Haimberger L, Healy SB, Hersbach H, Hölm EV, Isaksen L, Kallberg P, Köhler M, Matricardi M, McNally AP, Monge-Sanz BM, Morcrette JJ, Park PK, Peubey C, de Rosnay P, Tavolato C, Thêpaut JN, Vitart F (2011) The ERA-Interim reanalysis: configuration and performance of the data assimilation system. Q J R Meteorol Soc 137(656):553-597. https://doi.org/10.1002/qj.828

Donlon C, Martin M, Stark J, Roberts-Jones J, Fiedler E, Wimmer W (2012) The operational sea surface temperature and sea ice analysis (OSTIA) system. Remote Sens Environ 116:140-158. https://doi.org/10.1016/j.rse.2010.017

Giorgi F, Jones C, Asrar GR (2009) Addressing climate information needs at the regional level: the CORDEX framework. WMO Bull 58(3): $175-183$

Harrison DL, Driscoll SJ, Kitchen M (2000) Improving precipitation estimates from weather radar using quality control and correction techniques. Meteorol Appl 7:135-144. https://doi.org/10.1017/ S1350482700001468

Honnert R (2016) Representation of the grey zone of turbulence in the atmospheric boundary layer. Adv Sci Res 13:63-67. https://doi. org/10.5194/asr-13-63-2016

Keller M, Fuhrer O, Schmidli J, Stengel M, Stöckli R, Schär C (2016) Evaluation of convection-resolving models using satellite data: the diurnal cycle of summer convection over the Alps. Meteorol Z. https://doi.org/10.1127/metz/2015/0715

Kendon EJ, Roberts NM, Senior CA, Roberts MJ (2012) Realism of rainfall in a very high resolution regional climate model. J Clim 25:5791-5806. https://doi.org/10.1175/JCLI-D-11-00562.1

Kendon EJ, Roberts NM, Fowler HJ, Roberts MJ, Chan SC, Senior CA (2014) Heavier summer downpours with climate change revealed by weather forecast resolution model. Nat Clim Change 4:570 576. https://doi.org/10.1038/nclimate2258

Lean HW, Clark PA, Dixon M, Roberts NM, Fitch A, Forbes R, Halliwell C (2008) Characteristics of high-resolution versions of the met office unified model for forecasting convection over the United Kingdom. Mon Weather Rev 136:3408-3424. https://doi. org/10.1175/2008MWR2332.1

Leduc M, Laprise R (2009) Regional climate model sensitivity to domain size. Clim Dyn 32(6):833-854. https://doi.org/10.1007/ s00382-008-0400-z

Leduc M, Laprise R, Moretti-Poisson M, Morin JP (2011) Sensitivity to domain size of mid-latitude summer simulations with a regional climate model. Clim Dyn 37:343-356. https://doi.org/10.1007/ s00382-011-1008-2

Leutwyler D, Lüthi D, Ban N, Fuhrer O, Schär C (2017) Evaluation of the convection-resolving climate modeling approach on continental scales. J Geophys Res 122:5237-5258. https://doi. org/10.1002/2016JD026013

Lewis E (personal communications) personal communications

Lock AP, Webster S, Fosser G (personal communications) personal communications

Martins ES, Stedinger JR (2001) Generalized maximum likelihood pareto-poisson estimators for partial duration series. Water Resour Res 37(10):2551-2557. https://doi.org/10.1029/2001WR000367

Matte D, Laprise R, Thériault JM, Lucas-Picher P (2017) Spatial spinup of fine scales in a regional climate model simulation driven by low-resolution boundary conditions. Clim Dyn 49(1):563-574. https://doi.org/10.1007/s00382-016-3358-2 
Meinshausen M, Smith SJ, Calvin K, Daniel JS, Kainuma MLT, Lamarque JF, Matsumoto K, Montzka SA, Raper SCB, Riahi K, Thomson A, Velders GJM, van Vuuren DPP (2011) The RCP greenhouse gas concentrations and their extensions from 1765 to 2300. Clim Change 109:213-241. https://doi.org/10.1007/s1058 4-011-0156-z

Mizielinski MS, Roberts MJ, Vidale PL, Schiemann R, Demory ME, Strachan J, Edwards T, Stephens A, Lawrence BN, Pritchard M, Chiu P, Iwi A, Churchill J, Novales CDC, Kettleborough J, Roseblade W, Selwood P, Foster M, Glover M, Malcolm A (2014) High resolution global climate modelling: the UPSCALE project, a large simulation campaign. Geosci Model Dev 7:1629-1640. https://doi.org/10.5194/gmd-7-1629-2014

Neelin JD, Sahany S, Stechmann SN, Bernstein DN (2017) Global warming precipitation accumulation increases above the currentclimate cutoff scale. Proc Natl Acad Sci USA 114(6):1258-1263. https://doi.org/10.1073/pnas.1615333114

Ockenden MC, Deasy CE, Benskin CMH, Beven KJ, Burke S, Collins AL, Evans R, Falloon PD, Forber KJ, Hiscock KM, Hollaway MJ, Kahana R, Macleod CJA, Reaney SM, Snell MA, Villamizar ML, Wearing C, Withers PJA, Zhou JG, Haygarth PM (2016) Changing climate and nutrient transfers: Evidence from high temporal resolution concentration-flow dynamics in headwater catchments. Sci Total Environ 548-549:325-339. https://doi.org/10.1016/j.scito tenv.2015.12.086

Pall P, Allen MR, Stone DA (2007) Testing the Clausius-Clapeyron constraint on changes in extreme precipitation under $\mathrm{CO}_{2}$ warming. Clim Dyn 28:351-363. https://doi.org/10.1007/s0038 2-006-0180-2

Perry M, Hollis D, Elms M (2009) The generation of daily gridded datasets of temperature and rainfall for the UK. Met Office National Climate Information Centre, Exeter

Prein AF, Gobiet A, Suklitsch M, Truhetz H, Awan NK, Keuler K, Georgievski G (2013) Added value of convection permitting seasonal simulations. Clim Dyn 41:2655-2677. https://doi. org/10.1007/s00382-013-1744-6

Prein AF, Langhans W, Fosser G, Ferrone A, Ban N, Goergen K, Keller M, Tolle M, Gutjahr O, Feser F, Brisson E, Kollet S, Schmidli J, van Lipzig NPM, Leung R (2015) A review on regional convection-permitting climate modeling: demonstrations, prospects and challenges. Rev Geophys 53(2):323-361. https://doi. org/10.1002/2014RG000475

Svensson C, Jakob D (2002) Diurnal and seasonal characteristics of precipitation at an upland site in scotland. Int J Climatol 22:587598. https://doi.org/10.1002/joc.674

Trenberth KE, Dai A, Rasmussen RM, Parsons DB (2003) The changing character of precipitation. Bull Am Meteorol Soc 84(9):12051217. https://doi.org/10.1175/BAMS-84-9-1205

Trenberth KE, Zhang Y, Gehne M (2017) Intermittency in precipitation: duration, frequency, intensity, and amounts using hourly data. J Hydrometeorol 18(5):1393-1412. https://doi.org/10.1175/ JHM-D-16-0263.1

UKCP (2017) UKCP18 project announcement. http://ukclimateprojec tions.metoffice.gov.uk/24125. Accessed 15 Mar 2017 